\title{
Análise documental de fotografias jornalísticas: estudo exploratório dos elementos conotativos
}

\author{
Raquel Juliana Prado Leite de Sousa \\ Gabriela Aparecida da Cunha \\ Universidade Federal de São Carlos - UFSCar, Brasil.
}

\section{ARTIGOS / ARTICLE}

\begin{abstract}
Resumo
Reflete sobre a necessidade e a possibilidade de estabelecimento de maior rigor metodológico para a análise documental do processo conotativo de fotografias, tendo como objetivo realizar um estudo exploratório dos elementos de conotação. Analisa as fotografias presentes na cobertura jornalística de pesquisa científica que realizou estudo de arqueologia forense nos restos mortais dos imperadores brasileiros publicadas nos jornais O Estado de São Paulo e Folha de São Paulo em fevereiro de 2013. Parte do levantamento inicial da presença ou ausência dos elementos trucagem, pose, objetos, estetismo, sintaxe e fotogenia apontados por Barthes (1990) como formadores da conotação em fotografias jornalísticas, para posteriormente realizar análise conceitual de uma fotografia publicada nos dois jornais. Conclui que o estabelecimento de elementos para a análise e descrição do processo conotativo de fotografias deve e pode ser aprofundado, de modo a procurar, se não substituir, minimizar uma leitura subjetiva da conotação por critérios mais uniformes.
\end{abstract}

Palavras-chave

Análise documental de fotografia ; Processo de conotação ; Fotojornalismo

\section{Subject analysis of press photos: an exploratory study of the elements of connotation}

\begin{abstract}
This research reflects about the necessity and possibility of establishing of greater methodological rigor for the subject analysis of the connotation procedures in photos, aiming to conduct an exploratory study of the elements of connotation. It analyzes pictures in the media coverage of scientific research study of forensic archeology in the remains of Brazilian's emperors published in newspapers O Estado de São Paulo and Folha de São Paulo in February 2013. Initially, a survey was made in order to verify the presence or absence of trick effects, pose, objects, aestheticism, syntax, and photogenia, mentioned by Barthes (1990) as elements of connotation in press photos, then, was made a conceptual analysis of one photo published in the two newspapers. This paper concludes that the establishment of elements for the analysis and description of the connotation procedures in photos should be deepened in order to seek, if not replaced, minimizing a subjective reading of connotation by uniform criteria.
\end{abstract}

Keywords Title

Subject analysis of photos ; Connotation procedures ; Photojournalism 


\title{
1 Fotografia, jornalismo e memória
}

A habilidade de registrar e organizar informações, ideias, acontecimentos e outras vivências é intrínseca aos seres humanos e esteve presente desde os primórdios da civilização. A comunicação é, de fato, a maneira mais esplêndida que a humanidade encontrou para transmitir seus legados e ideais. Desde o início da história se observa que os seres humanos se comunicavam de maneiras diferenciadas, seja por meio da fala, do registro de símbolos, da escrita, de imagens, entre outras formas de comunicação sem as quais não seria possível a compreensão entre os indivíduos e o conhecimento da história, de maneira que os registros deixados pelos povos dão a possibilidade de entender e conhecer com mais fidelidade suas trajetórias, conquistas, culturas e costumes. Tem-se, então, a importância desses registros como memória, conforme essa conceituação:

A memória tem a propriedade de conservar certas informações, referentes a um conjunto de funções sócio-culturais ou psíquicas, com o poder de atualizar as impressões ou fatos passados. Essas informações podem significar, apenas, representações do passado formando a memória relativa à vida social; dos acontecimentos surgem e se acumulam documentos, monumentos, objetos e alegorias. (COSTA 2008, p. 17-18)

Tais fatores não seriam tão relevantes se os registros ficassem esquecidos no tempo, sem nenhum acesso; essas informações seriam perdidas e não promoveriam a geração do conhecimento. Costa (2008) ressalta as contribuições da Ciência da Informação para a organização de temas e conteúdos, de forma que se possam abstrair informações pertinentes que auxiliem no tratamento e na recuperação da informação registrada em toda a gama de suportes.

Uma das formas de comunicação e memória que merecem destaque em nossa sociedade é o jornalismo. Nascido da necessidade de relatar acontecimentos, teve como base inicial a escrita, a retórica e a historiografia, tornando-se uma linguagem própria e em constante transformação, pela inserção de recursos como fotografia, diagramação, infografia, etc. como forma de ampliar e diversificar as possibilidades de registro.

\begin{abstract}
Assim, pode dizer-se que o jornalismo vai buscar a sua origem mais remota aos tempos imemoriais em que os seres humanos começaram a transmitir informações e novidades e a contar histórias, quer por uma questão de necessidade (nenhuma sociedade, mesmo as mais primitivas, conseguiu sobreviver sem informação), quer por entretenimento, quer ainda para preservação da sua memória para gerações futuras (o que, simbolicamente, assegura a imortalidade). (SOUSA, 2008, p. 5)
\end{abstract}

Dentro da linguagem jornalística podemos destacar o fotojornalismo: nascido do casamento entre jornalismo e fotografia, adquiriu status de linguagem própria e diferenciada da fotografia como um todo, com seus estilos, épocas e técnicas diferenciadas. Em vista dessa afirmação e da possibilidade de abstrair conteúdos de jornais, tem-se neste trabalho a proposta de analisar e extrair conceitos que auxiliem na descrição de temas de fotografias jornalísticas enquanto informação sociocultural, que agrega tanto informações factuais quanto históricas, tecnológicas, de pesquisa, ideológicas, etc.

A fotografia de imprensa possui particularidades não apenas referentes aos meios de produção e publicação, mas também pelo caráter simbólico que desempenha frente à comunicação social e à memória, tendo influenciado não somente nossa forma de ver o mundo, mas também nossa forma de fotografá-lo. Conforme Torregrosa Carmona (2010), a fotografia jornalística contribuiu poderosamente ao longo dos tempos para mudar a própria concepção de imagem fotográfica, mais do que outros tipos de fotografia, como a artística ou a científica, por exemplo. A foto denúncia, a fotorreportagem e spot news são alguns exemplos de gêneros que mudaram o que definimos como forma de fotografar. Assim, justifica-se a necessidade de tratamento documental de fotografias jornalísticas que deem conta não apenas da descrição de suas particularidades extrínsecas, mas também de suas particularidades referentes ao conteúdo. Dessa forma, o objetivo do presente trabalho é explorar a análise documental de fotografias publicadas em jornais, a fim de refletir sobre a necessidade e a possibilidade de estabelecer elementos para análise do processo de conotação, tendo se valido dos procedimentos conotativos apontados por Barthes (1990), os quais foram agregados ao quadro teórico de análise documental de imagens proposto por Costa (2008) e utilizado por Cóscia (2012). 


\section{0 fotojornalismo e a verdade falseada}

O conceito de fotografia de imprensa tem se transformado ao longo dos anos, pelas mudanças técnicas e estilísticas e pela inserção, cada vez maior, de imagens captadas por fotógrafos amadores e processos não fotográficos propriamente ditos, "portanto, quando o leitor leigo folheia displicentemente seu jornal, está longe de imaginar que tem diante dos olhos um formidável resumo de toda a evolução da fotografia no século XX. Ou até mesmo do século XIX." (VASQUEZ, 2011, p. 122).

De acordo com Sousa (1998), as primeiras manifestações fotojornalísticas se deram quando da ideia de testemunhar acontecimentos, fazendo-os chegar ao grande público. A fotografia chegou à imprensa, provavelmente, a partir de 1842; entretanto, no princípio do fotojornalismo, as fotos eram redesenhadas como gravuras para serem reproduzidas nas páginas dos jornais e revistas. Só no final do século XIX, pela melhoria das técnicas de impressão (zincogravura), a imagem fotográfica pôde ser mimeticamente estampada (SOUSA, 1998). Foi com a invenção do colódio úmido que se possibilitou a duplicação da imagem fotográfica pelo processo negativo/positivo, inserindo-a definitivamente como testemunho documental nos jornais. Podem-se citar como marcos dessa época as coberturas da guerra da Crimeia (1855), da guerra da Secessão (1862-1865) e do julgamento e execução de conspiradores a favor do assassinato de Abraham Lincoln (1865) (VASQUEZ, 2012).

Cada evolução técnica no processo fotográfico agregou mudanças na forma de expressão da imagem, permitindo que os fotojornalistas fossem a lugares novos e mais distantes, chegassem cada vez mais rapidamente, fizessem mais exposições, reproduzissem mais cópias e publicassem com mais velocidade e qualidade, o que acabou por reforçar o imediatismo do jornalismo e seu (pseudo) caráter objetivo e imparcial.

Para o fotojornalismo, a conquista do movimento revelou-se de importância vital, uma vez que permitiu "congelar" a acção, impressioná-la numa imagem quase em tempo real, capturar o imprevisto, chegar ao instantâneo e, com ele, acenar com a ideia de verdade: o que é assim capturado seria verdadeiro; a imagem não mentiria [...] (SOUSA, 1998, p. 22)

Entretanto, a própria transposição do paradigma da doutrina scoop (a foto única, exclusiva, o furo de reportagem), acabou por evidenciar uma 'verdade falseada' presente na fotografia: pela comparação de diversas coberturas fotográficas e enfoques do mesmo acontecimento, o leitor pôde começar a comparar as diversas fotografias e perceber que, apesar do referente poder ser o mesmo, o(s) sentido(s) da imagem pode(m) ser diferente(s).

Apesar de já ser ultrapassada a ideia de fotografia como reprodução objetiva da realidade, é inegável o impacto do fotojornalismo enquanto testemunho: as coberturas das guerras no final do século XIX e início do século XX, com fotografias das vítimas e da devastação deixada pelos combates, chocaram o mundo e revelaram um horror antes inimaginável à população civil.

Anos mais tarde, revistas de variedades, com coberturas de festas e vidas de celebridades vão ajudar a vender 0 sonho da prosperidade, o americam way of life, e dar a base para a criação da imprensa rosa, em voga até os dias atuais.

No final do século $X X$, pela popularização das câmeras fotográficas, os leitores passam de receptores passivos de imagens e começam a enviar suas fotos para os jornais. Novas tecnologias permitem que, além de fotografias, toda a sorte de imagens possa chegar às páginas dos jornais, sendo reproduzidas como fotos (imagens isoladas de vídeos, ultrassons, ressonâncias, etc.).

A própria fotografia digital, inserida definitivamente nos jornais em 1995 quando o Vancouver Sun decidiu trabalhar exclusivamente com câmeras digitais (VASQUEZ, 2012), foi alvo de polêmica entre os estudiosos do assunto, uma vez que ela não se utiliza do mesmo suporte, tendo causado discussões sobre a fácil manipulação através de softwares de edição, o que poderia ameaçar a retratação da realidade (BUITONI, 2011; VASQUEZ, 2012).

A fotografia assume, junto com o jornalismo, uma posição de transmitir à sociedade informações de expressão visual acerca de acontecimentos sortidos. Essa é uma possibilidade abrangente dos jornais, em que a fotografia se torna parte da narrativa, de maneira a auxiliar na construção da significação. Assim, como afirma Agostineti a respeito da construção da significação: 
o jornalista constrói, a partir das informações acerca de um fato, textos em várias linguagens e gêneros. Essa construção é uma maneira de traduzir o acontecimento ressignificado em matérias jornalísticas, o que posiciona o jornalismo como uma categoria narrativa do mundo, fato que pode ser notado em uma simples análise. (AGOSTINETI, 2010, p. 3)

Entretanto, para Barthes (1990), a imagem fotográfica não é o real, mas é seu analogon perfeito: é uma mensagem sem código que expõe, ao mesmo tempo, uma mensagem denotativa (pela exibição do conteúdo fotografado) e uma mensagem conotativa (pela exibição de um conteúdo suplementar, culturalmente definido pela sociedade em que está inserida).

\section{Referencial teórico}

A Biblioteconomia e a Ciência da Informação têm como um dos principais objetivos o tratamento e a disseminação de informações de qualquer espécie. A fotografia enquanto registro é uma fonte de informação que precisa de, assim como outros suportes (livros, periódicos, obras de artes), um tratamento bibliográfico que possibilite sua descrição, representação e consequente acesso. Entretanto, o tratamento documental despendido ao texto verbal já se provou ineficiente para o trabalho com documentos fotográficos. Retomando a ideia de Barthes (1990) de que a fotografia é uma mensagem sem código, tentar descrevê-la através da linguagem, imputando-lhe um código linguístico, artificial à sua essência, é um desafio que pode se tornar inexequível, em especial se não se possui essa consciência.
A informação registrada visualmente configura-se num sério obstáculo tanto para o pesquisador que trabalha no museu ou arquivo como ao pesquisador usuário que freqüenta essas instituições. O problema reside justamente na sua resistência em aceitar, analisar e interpretar a informação quando esta não é transmitida segundo um sistema codificado de signos em conformidade com os cânones tradicionais da comunicação escrita. (KOSSOY, 2009, p. 30)

Junta-se a essa problemática a questão da dificuldade em demarcar claramente a divisão entre forma e conteúdo nos documentos fotográficos (SMIT, 1996), uma vez que a forma também é formadora do conteúdo da fotografia. Recursos de iluminação, profundidade de campo, focagem, filtros, etc., são criadores do conteúdo informacional. Dentre os trabalhos com a análise documental de imagens, percebe-se a crescente preocupação com estudos que visam ao refinamento de metodologias que deem conta de diminuir a subjetividade da análise e descrição de seu conteúdo, a fim de facilitar as possibilidades de acesso a esses documentos.

De acordo com Smit (1996), as categorias Quem, O que, Como, Onde e Quando, utilizadas por vários teóricos para a análise de textos verbais, também é útil para a descrição de documentos imagéticos. Para este trabalho, foi dada atenção especial a tais categorias, uma vez que essas também são o cerne do texto jornalístico, figurando como os elementos essenciais na construção de lides das notícias e notas. Partindo do cotejamento entre tais categorias às essências PMEST ranganathianas, encontra-se relação direta entre: Quem/Personalidade; O que/ Matéria; Como/ Energia; Onde/ Espaço; e Quando/ Tempo (COSTA, 2008). Dessa forma, durante a análise conceitual, as categorias foram utilizadas para a abordagem da fotografia e também do texto jornalístico, a fim de identificar os conceitos inerentes à imagem.

Dentre as grades de análise propostas para a descrição de imagens na Biblioteconomia e na Ciência da Informação, selecionou-se, para esta pesquisa, o quadro proposto por Costa (2008) para a análise de cartazes publicitários, utilizado posteriormente por Cóscia (2012) para a análise de fotografias.

Um dos maiores desafios para a representação temática de imagens é ultrapassar a mera descrição dos elementos denotativos, pela simples listagem de objetos e personagens presentes, e tentar circunscrever os elementos conotativos, ou seja, o significado simbólico além do vínculo óbvio entre o objeto e o sentido. Há, segundo Cóscia (2012), uma grande dificuldade no processo da análise e descrição de imagens que é a separação do que é denotativo e o que é conotativo, influenciado ainda pelas legendas ou pelo contexto, podendo conduzir a interpretações pessoais e indevidas. Isso se dá, também, porque a conotação pode se fazer passar por denotação (BARTHES, 1990), ou, dito de outra forma, o sentido conotativo é expresso justamente pela presença de elementos denotativos e esses dois ou mais sentidos carregados por um elemento único tornam a imagem polissêmica e dificultam a separação entre denotação e conotação, pois, em rigor, essa dicotomia não existe. 
A respeito dessa problemática, o presente estudo se baseou na teoria semiótica de Barthes (1990), mais especificamente nos procedimentos de conotação da mensagem fotojornalística, que abrangem:

- $\quad$ Trucagem - No processo de trucagem há uma intervenção na denotação, de forma a criar um sentido diferente do real, se não oposto, sendo, na realidade, uma imagem intensamente conotada. Essa intervenção se dá pela sobreposição ou supressão de determinados planos ou objetos na fotografia. O fotojornalista associa de modo 'artificial' duas imagens em uma, na hora da exposição ou posteriormente, com uso de técnicas de revelação ou utilização de softwares de tratamento de imagens, de maneira a criar uma nova realidade. A partir dessa associação, acresce-se um outro sentido à imagem (ex.: junção das fotografias de um prédio e de chamas, de modo a criar a imagem do prédio sendo incendiado).

- Pose - Esse processo envolve uma bagagem cultural que é necessária para a compreensão do que é convencionado na fotografia jornalística. Ele se dá pela captura de gestos que sugerem a significação da conotação, Barthes (1990, p. 16-17) afirma que: "[...] é significante porque nela existe um conteúdo de atitudes estereotipadas que constituem elementos cristalizados de significação [...]", ou seja, no momento em que a imagem foi registrada, os elementos da fotografia encontram-se posicionados, ou fazendo gestos, de modo que inferem um sentido de uma situação que já conhecemos, ou que nos é familiar. (ex.: um homem ajoelhado frente a uma mulher dá o sentido de homem se declarando apaixonado).

- Objetos - O sentido da conotação está, certamente, nos objetos fotografados, ressaltando a presença deles de maneira a valorizá-los na imagem registrada. De forma que esses objetos sejam indutores de geração de sentido ou associação de ideias. Eles reportam, de acordo com Barthes (1990, p. 17), "[...] a significantes claros, conhecidos; são, pois, elementos de um verdadeiro léxico, estáveis a ponto de se poder facilmente estabelecer sua sintaxe." Em outras palavras, pode-se dizer que os objetos são 'organizados' na fotografia de maneira a induzir uma ideia. (ex.: a presença livros sobre uma mesa remete a estudo, intelectualidade).

- Fotogenia - Esse processo de conotação de imagem se dá pelo uso de recurso como: enquadramento, composição, iluminação e velocidade do obturador. A utilização desses recursos é capaz de "embelezar" a imagem, favorecendo os elementos da fotografia e tornando belo algo que na realidade pode não ser, ou o contrário (ex.: a iluminação pode suavizar ou esconder as rugas de uma pessoa, dando a sensação de que ela é mais jovem do que na realidade, ou realçar rugas e manchas da pele, dando a ideia de personagem marcado pelas experiências da vida ou cansado e embrutecido).

- Estetismo - A composição do sentido no processo de conotação do estetismo está baseada no abuso da estética da fotografia, a ponto dela se assemelhar a uma pintura artística pelo modo como ela foi composta e registrada (composições geométricas) ou pelo uso de efeitos como iluminação. São imagens que lembram ou nos remetem a obras de artes (ex.: pessoas dispostas ao redor de uma mesa de banquete remetem ao afresco 'A Última Ceia', de Leonardo da Vinci).

- Sintaxe - O processo de sintaxe se dá pela disposição orientada de imagens. O sentido, nesse processo, está fortemente ligado ao encadeamento das imagens em sequências, de maneira que se fossem analisadas separadamente, fora da sequência, provavelmente não seriam atribuídos os mesmos sentidos (ex.: sequência de fotos que mostram um jogador de futebol posicionado para marcar um pênalti, chutando a bola e depois acertando o gol). 


\section{Procedimentos metodológicos}

A partir de trabalhos científicos como o de Barthes (1990), Smit (1996), Costa (2008) e Cóscia (2012), foi possível refletir a respeito da necessidade de um tratamento bibliográfico para fotografias jornalísticas.

Dessa necessidade foram escolhidos dois jornais de grande circulação brasileiros, que em dias diferentes, apresentavam reportagens semelhantes sobre a exumação dos corpos da família real portuguesa para pesquisa. Foram escolhidos O Estado de São Paulo, que publicou a reportagem intitulada "Exumação inédita de Dom Pedro e suas 2 mulheres reconta detalhes da História" (2013) em 19 de fevereiro, e a Folha de São Paulo, com notícia publicada em 20 de fevereiro, intitulada "Corpos da família imperial são exumados" (2013). Esses jornais traziam fotos sobre a pesquisadora, Valdirene Ambiel, que exumou os corpos de D. Pedro, Dona Leopoldina, Dona Amélia, incluindo as fotos de alguns procedimentos utilizados em sua pesquisa. Como os dois jornais traziam algumas fotos semelhantes e até iguais, foi possível fazer uma comparação entre os processos e a utilização feita por eles ${ }^{1}$.

Na primeira etapa das análises, as imagens dos dois jornais foram listadas separadamente, a fim de verificar e quantificar quais processos de conotação (BARTHES, 1990) apareciam em cada uma das fotografias, tomando como base o quadro 1 :

\begin{tabular}{|l|l|}
\hline Processo de conotação & Fotografia n.-﹎- \\
\hline Trucagem & \\
\hline Pose & \\
\hline Objetos & \\
\hline Fotogenia & \\
\hline Estetismo & \\
\hline Sintaxe & \\
\hline
\end{tabular}

Quadro 1 - grade para verificação quantitativa dos processos de conotação presentes nas fotos. Fonte: elaborado pelo autor.

Após essa categorização, houve a necessidade da elaboração de um novo quadro que agrupasse os conceitos abordados por Barthes (1990), com outras categorias de análise, a fim de levantar o conteúdo temático das fotografias. Dessa forma, foi feita a junção do quadro analítico proposto por Costa (2008) e dos processos de conotação descritos por Barthes (1990). No quadro de Costa (2008), a coluna 'conotação' foi trocada por seis colunas, cada uma correspondente a um processo de conotação descrito por Barthes (1990). Assim, onde houve o intercruzamento das categorias PMEST de Ranganathan, utilizadas nos estudos de Costa (2008) e Cóscia (2012) aos processos conotativos de Barthes (1990), como visto no quadro 2. Também foi trocada a expressão 'descritores' por 'conceitos', uma vez que não se utilizou nenhuma linguagem documentária para a descrição, tendo sido apenas levantados os conceitos referentes aos temas encontrados em cada categoria. 


\begin{tabular}{|c|c|c|c|c|c|c|c|}
\hline \multicolumn{8}{|l|}{ Nome do jornal } \\
\hline \multicolumn{8}{|l|}{ 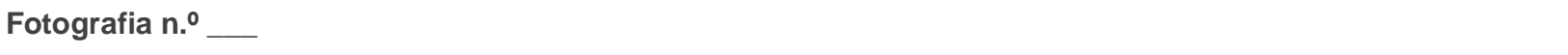 } \\
\hline \multirow{3}{*}{ Categorias de Análise } & \multicolumn{7}{|l|}{ Conceitos } \\
\hline & \multirow[b]{2}{*}{ Denotativo } & \multicolumn{6}{|l|}{ Conotativo } \\
\hline & & Trucagem & Pose & Objetos & Estetismo & Sintaxe & Fotogenia \\
\hline \multicolumn{8}{|l|}{$\begin{array}{l}\text { Personalidade: } \\
\text { personagens, atores, } \\
\text { onomástico (Quem?) }\end{array}$} \\
\hline \multicolumn{8}{|l|}{$\begin{array}{l}\text { Matéria: objeto, } \\
\text { expressão, tema, } \\
\text { enredo } \\
\text { (O quê?) }\end{array}$} \\
\hline \multicolumn{8}{|l|}{$\begin{array}{l}\text { Energia: ação, evento, } \\
\text { acontecimento } \\
\text { (Como?) }\end{array}$} \\
\hline \multicolumn{8}{|l|}{$\begin{array}{l}\text { Espaço: ambiente, } \\
\text { cenário, topográfico } \\
\text { (Onde?) }\end{array}$} \\
\hline $\begin{array}{l}\text { Tempo: cronológico, } \\
\text { histórico, psicológico } \\
\text { (Quando?) }\end{array}$ & & & & & & & \\
\hline
\end{tabular}

Quadro 2 - grade de análise proposta. Fonte: elaborado pelo autor.

Ressalta-se que a análise implicou na leitura não só da fotografia, mas também de conceitos de diagramação, texto e legenda dos jornais, o que possibilitou uma descrição mais detalhada no terceiro procedimento da pesquisa, pois "[...] a estrututa da fotografia não é uma estrutura isolada; identifica-se, pelo menos, com uma outra estrutura, que é o texto (título, legenda ou artigo) que acompanha toda fotografia jornalística" (BARTHES, 1990, p. 12).

O terceiro procedimento foi escolher uma fotografia que estivesse presente nos dois jornais, para descrever com palavras os conceitos gerados pela presença dos indicadores de conotação de Barthes (1990). Por fim, foi feito um resumo da fotografia escolhida, tendo como base os conceitos levantados através da análise das fotografias e dos textos dos dois jornais.

É importante destacar que, durante a pesquisa, percebeu-se que a fotografia escolhida não havia sido feita no intuito de ser uma fotografia jornalística, mas sim para documentar a pesquisa arqueológica realizada por Ambiel (2013). Entretanto, quando veiculada em uma matéria jornalística, adquire o status de fotografia de imprensa, pela junção com os demais elementos constituintes das matérias, os quais formam o discurso jornalístico. 


\section{Considerações sobre a análise exploratória}

Ressalta-se que a análise e o resumo da imagem se deram apenas com base nas informações contidas nos jornais, sendo que a dissertação de Ambiel (2013) foi utilizada somente para descrição de sua produção original. Dessa forma, se a dissertação fosse usada como fonte de pesquisa, a descrição certamente traria expressões mais específicas quanto a equipamentos, técnicas, etc. Isso se justifica uma vez que o objetivo do estudo é explorar a análise da imagem enquanto reprodução publicada como fotografia em texto jornalístico, ou seja, para transmitir mensagens jornalísticas ao grande público, e não enquanto documento de comprovação científica.

Na referida reportagem, O Estado de São Paulo publicou dez fotografias (EXUMAÇÃO..., 2013); a partir do quadro 1, foi observado que houve a ocorrência de cinco fotos que continham a categoria trucagem, seis com a categoria pose, três com objetos, uma com fotogenia e duas com estetismo.

A Folha de São Paulo publicou nove fotografias (CORPOS..., 2013), onde houve a ocorrência de cinco com a categoria pose, duas com objeto, uma como estetismo e quatro com sintaxe. Esse jornal apresenta um boxe com quatro fotos em sequência, que dão a ideia das etapas da pesquisa arqueológica.

Notou-se que não houve cobertura fotojornalística para as matérias, ou seja, as imagens usadas foram cedidas pela pesquisadora e não realizadas por profissionais dos jornais. Apenas o Estado de São Paulo apresentou duas fotos especialmente feitas para a reportagem: um retrato do marceneiro que construiu um novo ataúde para o imperador e um retrato de uma cidadã, que deu seu depoimento sobre a importância da preservação dos restos mortais. Isso se deveu ao fato de que a pesquisa foi feita em sigilo, tendo a imprensa sido informada apenas após seu término, o que não deu a oportunidade dos fotojornalistas e repórteres acompanharem de perto o estudo.

A imagem escolhida para o trabalho exploratório dos processos de conotação foi a fotografia da pesquisadora responsável pelo estudo (figura 1), a qual foi reproduzida nos dois jornais. Primeiramente, foi analisada essa fotografia no contexto de cada jornal, sendo elaborado dois quadros de análise. Em seguida, foi feita a junção das duas análises, concluída com uma descrição única e um resumo (quadro 3).

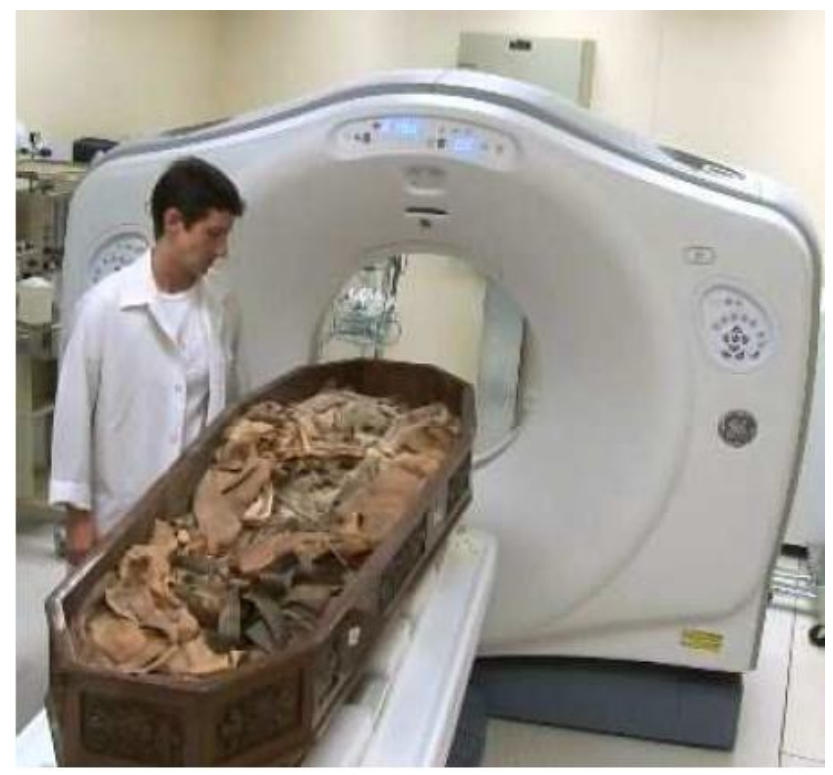

Figura 1 - imagem veiculada nos jornais O Estado de São Paulo e Folha de São Paulo. Fonte: Ambiel (2013).

\subsection{Resumo da fotografia apresentada nos dois jornais:}

Fotografia colorida, de caráter não espontâneo, obtida por aparelho de filmagem, tendo sido captada por Valter D. Muniz e reproduzida como fotografia na página 94 da dissertação intitulada "Estudos de arqueologia forense aplicados aos remanescentes humanos dos primeiros imperadores do Brasil depositados no Monumento à Independência", do Programa de Pós-graduação em Arqueologia do museu de Arqueologia e Etnologia da 
Universidade de São Paulo, de autoria da pesquisadora Valdirene do Carmo Ambiel. A imagem foi reproduzida como fotografia em jornais de grande circulação do estado de São Paulo a citar: A Folha de São Paulo, cuja publicação data-se de 20 de Fevereiro de 2013, e O Estado de São Paulo, datado de 19 de Fevereiro de 2013. A imagem foi feita em ambiente fechado, na sala de tomografia do Departamento de Radiologia do Hospital das Clínicas de São Paulo. Valdirene do Carmo Ambiel observa o cadáver de Dona Leopoldina, esposa de D. Pedro I, após a exumação do corpo para sua pesquisa de mestrado em março de 2012. O caixão de madeira entalhado com o cadáver envolto por panos encontra-se perpendicular ao aparelho de tomografia e alinhado ao eixo vertical e horizontal, o aparelho aparece no segundo plano da fotografia. Valdirene está disposta em pé do lado esquerdo da fotografia, de perfil, em frente ao aparelho e ao lado do caixão. A pesquisadora veste uma camiseta branca sob um jaleco branco de mangas longas e dobradas no punho, com botões abertos. Apresenta cabelos curtos, escuros e aparentemente lisos. Valdirene apresenta um olhar atento e observador. Ao fundo, atrás da pesquisadora e do caixão, há o aparelho de tomografia branco e digital, com uma abertura em forma de círculo, onde é possível notar mais algum aparelho hospitalar por esta abertura. O caixão está em cima da esteira do aparelho de base azul.

\section{O Estado de São Paulo/ Folha de São Paulo}

Fotografia $\mathbf{n} .^{\circ}$

\begin{tabular}{|c|c|c|c|c|c|c|c|}
\hline \multirow{3}{*}{$\begin{array}{l}\text { Categorias de } \\
\text { análise }\end{array}$} & \multicolumn{7}{|l|}{ Conceitos } \\
\hline & \multirow{2}{*}{ Denotativo } & \multicolumn{6}{|l|}{ Conotativo } \\
\hline & & Trucagem & Pose & Objetos & Estetismo & Sintaxe & Fotogenia \\
\hline $\begin{array}{l}\text { Personalida-de: } \\
\text { personagens, } \\
\text { atores, } \\
\text { Onomástico } \\
\text { (Quem?) }\end{array}$ & $\begin{array}{l}\text { Valdirene do } \\
\text { Carmo Ambiel } \\
\text { (pesquisadora, } \\
\text { historiadora e } \\
\text { arqueóloga), } \\
\text { D. Leopoldina }\end{array}$ & & $\begin{array}{l}\text { Supervisão do } \\
\text { exame de } \\
\text { tomografia, } \\
\text { Observação, } \\
\text { Postura de } \\
\text { pesquisa-dora }\end{array}$ & $\begin{array}{l}\text { Roupas de } \\
\text { cientista/médi } \\
\text { ca (jaleco e } \\
\text { roupas } \\
\text { brancas) }\end{array}$ & & & \\
\hline $\begin{array}{l}\text { Matéria: objeto, } \\
\text { expressão, } \\
\text { tema, enredo } \\
\text { (O quê?) }\end{array}$ & $\begin{array}{l}\text { Tomógrafo, } \\
\text { Restos mortais } \\
\text { de D. Leopol-dina }\end{array}$ & & $\begin{array}{l}\text { Relação } \\
\text { pesqui-sadora/ } \\
\text { objeto de } \\
\text { estudo }\end{array}$ & $\begin{array}{l}\text { Aparelho } \\
\text { sofisticado, } \\
\text { Restos } \\
\text { mortais muito } \\
\text { antigos e } \\
\text { deteriora-dos }\end{array}$ & & & $\begin{array}{l}\text { Enquadra- } \\
\text { mento, } \\
\text { Recorte de } \\
\text { parte do } \\
\text { cenário, } \\
\text { Tomógrafo } \\
\text { domina a } \\
\text { maior parte da } \\
\text { imagem }\end{array}$ \\
\hline $\begin{array}{l}\text { Energia: ação, } \\
\text { evento, } \\
\text { aconteci-mento } \\
\text { (Como?) }\end{array}$ & $\begin{array}{l}\text { Pesquisa, } \\
\text { Observação, } \\
\text { Exame de } \\
\text { tomografia }\end{array}$ & & $\begin{array}{l}\text { Acompanha- } \\
\text { mento da } \\
\text { tomografia, } \\
\text { Seriedade }\end{array}$ & $\begin{array}{l}\text { Pesquisa de } \\
\text { ponta, Inédita }\end{array}$ & & $\begin{array}{l}\text { Etapa dos } \\
\text { procedi- } \\
\text { mentos de } \\
\text { pesquisa }\end{array}$ & \\
\hline $\begin{array}{l}\text { Espaço: } \\
\text { ambiente, } \\
\text { cenário, } \\
\text { topográfico } \\
\text { (Onde?) }\end{array}$ & $\begin{array}{l}\text { Sala de radiologia } \\
\text { do Hospital das } \\
\text { Clínicas de São } \\
\text { Paulo }\end{array}$ & & $\begin{array}{l}\text { Atrás do } \\
\text { tomógrafo, } \\
\text { Defronte aos } \\
\text { restos mortais, } \\
\text { Aguardando }\end{array}$ & $\begin{array}{l}\text { Sala de } \\
\text { tomografia, } \\
\text { Ambiente de } \\
\text { pesquisa } \\
\text { científica }\end{array}$ & & & \\
\hline $\begin{array}{l}\text { Tempo: } \\
\text { cronológico, } \\
\text { histórico, } \\
\text { psicológico } \\
\text { (Quando?) }\end{array}$ & $\begin{array}{l}2012,19 \text { e } 20 \text { de } \\
\text { março }\end{array}$ & & & $\begin{array}{l}100 \text { anos } \\
\text { após a morte, } \\
\text { Deteriora-ção }\end{array}$ & & $\begin{array}{l}\text { Uma das } \\
\text { fases dos } \\
\text { procedi- } \\
\text { mentos de } \\
\text { pesquisa }\end{array}$ & \\
\hline
\end{tabular}

Quadro 3 - análise da fotografia selecionada. 


\section{Considerações finais}

Devido à preocupação com a subjetividade da análise e descrição de conteúdo de imagens, o presente trabalho propõe a análise e a extração de conceitos que auxiliem na descrição de conteúdos de fotografias jornalísticas, tendo como objetivo a exploração da análise documental de fotografias publicadas em diferentes jornais, apoiandose nos processos de conotação de Barthes (1990) agregados aos quadros de análise propostos por Costa (2008) e Cóscia (2012), com a finalidade de ampliar e/ou facilitar o acesso a tais documentos. Assim, fizeram-se necessárias discussões acerca da importância da conservação de registros como memória sociocultural, do fotojornalismo, e da fotografia como parte da narrativa, influenciando na construção da significação.

Através dessa análise proposta para a descrição de imagens na Biblioteconomia e na Ciência da Informação, pôdese observar que o intercruzamento entre os elementos de conotação propostos por Barthes (1990) ao quadro citado possibilita a descrição não apenas dos elementos denotativos da fotografia, mas também dá a possibilidade de refletir sobre um maior rigor metodológico para a descrição dos elementos conotativos. O presente trabalho é fruto de um estudo inicial que se propõe refletir sobre elementos mais objetivos para a análise e descrição do processo de conotação de fotografias, carecendo de mais aprofundamento em etapas futuras.

A fotografia escolhida, a mesma nos dois jornais, revelou que os elementos de denotação e conotação se relacionam, dando a possibilidade de evidenciar os conceitos conotativos.

Verifica-se que o conceito de Pose esteve presente em quatro das categorias analisadas, sendo elas: Personalidade, Matéria, Energia e Espaço. Através dos gestos sugeridos pela pesquisadora, sendo o modo como ela se dispõe ao lado do objeto de estudo e ao lado do aparelho de tomografia, sugerindo alguns conceitos como a relação cientista-objeto e a supervisão de exames.

O conceito de Objetos apresenta-se nas cinco categorias: o jaleco e as roupas brancas fazem a associação de sentido à seriedade da cientista e sua pesquisa, os restos mortais, em associação ao aparelho de tomografia, indicam que não se trata de um exame médico, mas sim de uma pesquisa, de modo que, se fosse apenas uma foto comum da pesquisadora, sem esses objetos, não haveria essa possibilidade de associação de ideias. Se não houvesse a presença dos restos mortais, o sentido 'pesquisa científica' não seria evidente, pois o tomógrafo seria o objeto em destaque, o que daria o sentido de 'exame médico'. Da mesma forma, se o tomógrafo não estivesse presente, mas apenas os restos mortais, o tipo de pesquisa realizada, inédita no Brasil, não seria evidenciada.

O conceito de sintaxe é apresentado no jornal A Folha de São Paulo em duas categorias (Energia e Tempo), de maneira que a imagem selecionada para análise está disposta dentro de uma sequência de quatro fotos a respeito da pesquisa, o que revela os procedimentos que foram utilizados e desenvolvidos pela pesquisadora na exumação dos corpos Reais no espaço e no tempo.

Por fim, verificou-se o uso de recursos como enquadramento e recorte de parte do cenário fotografado, sendo o conceito de Fotogenia utilizado na categoria Matéria, uma vez que o tomógrafo toma o espaço da imagem, aparecendo nos três terços horizontais e nos três verticais, ficando sua abertura centralizada, o que reforça a importância do aparelho para a realização da pesquisa.

Por mais óbvios que alguns conceitos levantados possam parecer, ressalta-se que o presente estudo procura explorar a análise do processo de conotação em fotografias, no intuito de refletir sobre a necessidade e a possibilidade de criar elementos mais objetivos (ou menos subjetivos) que deem conta de estabelecer maior rigor metodológico, a fim de substituir a 'intuição' do bibliotecário por critérios que possam uniformizar e o otimizar a análise documental.

Entretanto, vale ressaltar, novamente, a dificuldade da descrição de assuntos de documentos imagéticos para fins documentários, de modo que a substituição completa da 'intuição' talvez nunca seja alcançada.

[...] a descrição de uma fotografia é, ao pé da letra, impossível, pois descrever consiste precisamente em acrescentar à mensagem denotada um relais ou uma segunda mensagem, extraída de um código, que é a língua, e que constitui, fatalmente, qualquer que seja o cuidado que se tenha para ser exato, uma conotação em relação ao análogo fotográfico: é mudar de estrutura, é significar uma coisa diferente daquilo que é mostrado. (BARTHES, 1990, p. 14) 
A descrição da imagem é impossível ao pé da letra, mas isso não deve ser um impedimento ao trabalho do bibliotecário, pois a análise e a representação para fins documentários é uma necessidade. Se ao descrever uma fotografia com palavras atribuímos a ela uma conotação, impondo um sentido outro, devemos estar lúcidos desse fato, além de sabermos por que e para quem descrevemos.

A representação documentária, dentro da Biblioteconomia e da Ciência da Informação, per se, já é uma mudança de estrutura, é a imputação de uma segunda mensagem, extraída de códigos de representação documentária. Atribuir pontos de acesso a qualquer tipo de documento é mudar da estrutura do livro, do periódico, do mapa, do microfilme, para a estrutura do catálogo bibliográfico, mostrando e significando conceitos diferentes que só existem dentro de unidades de informação.

A fotografia se constitui a partir de uma conexão física com o seu referente: ela é um traço que atesta a existência daquele objeto naquele momento. Ela não explica nada, não interpreta: simplesmente mostra. Há um jogo de duas formas que aparentemente se excluem: uma presença que afirma uma ausência e uma ausência que afirma uma presença. (BUITONI, 2011, p. 24)

Não é esse também o jogo da representação da informação?

\section{Bibliografia}

AGOSTINETI, K. Fotorreportagem: a apropriação imagética da narrativa jornalística. In: CONGRESSO BRASILEIRO DE CIÊNCIAS DA COMUNICAÇÃO, 33., 2010, Caxias do Sul. Anais eletrônicos... Caxias do Sul: 2010. Disponível em: <http://www.intercom.org.br/sis/2010/resumos/R5-1335-1.pdf>. Acesso em: 25 fev. 2013.

AMBIEL, V. C. Estudos de arqueologia forense aplicados aos remanescentes humanos dos primeiros imperadores do Brasil depositados no Monumento à Independência. 2013. 253 f. Dissertação (Mestrado em Arqueologia)-Universidade de São Paulo, São Paulo, 2013.

BARTHES, R. A mensagem fotográfica. In: Nova Fronteira, 1990. p. 11-61. . O óbvio e o obtuso: ensaios críticos III. Léa Novaes (Trad.). Rio de Janeiro:

BUITONI, D. S. Fotografia e jornalismo: a informação pela imagem. São Paulo: Saraiva, 2011.

CORPOS da família imperial são exumados. Folha de São Paulo, São Paulo, ano 93, n. 30.639, caderno Ciência+Saúde, p. c9, 20 fev. 2013.

CÓSCIA. V. L. Análise de fotografias: Florestan Fernandes no tempo da ditadura militar. 2012. 144 f. Dissertação (Mestrado em Ciência, Tecnologia e Sociedade)-Universidade Federal de São Carlos, São Carlos, 2012.

COSTA, L. S. F. Uma contribuição da Teoria Literária para a análise de conteúdo de imagens publicitárias do fim do século XIX e primeira metade do século XX, contemplando aspectos da natureza brasileira. 2008. 261 f. Tese (Doutorado em Ciência da Informação)-Universidade Estadual Paulista, Marília, 2008.

EXUMAÇÃO inédita de Dom Pedro e suas 2 mulheres reconta detalhes da História. O Estado de São Paulo, São Paulo, ano 134, n. 43.589, caderno Cidades, p. 31/33-35, 19 fev. 2013.

KOSSOY, B. Fotografia \& história. 3. ed. rev. amp. São Paulo: Ateliê Editorial, 2009.

SOUSA, J. P. Uma história crítica do fotojornalismo ocidental. Porto: Biblioteca On-Line de Ciências da Comunicação, 1998. Disponível em: <http://www.bocc.ubi.pt/pag/ texto.php?html2=sousa-iorge-pedro-historia fotojorn1.html>. Acesso em: 20 jul. 2013.

Uma história breve do jornalismo no ocidente. Porto: Biblioteca On-Line de Ciências da Comunicação, 2008. Disponível em: <http://www.bocc.ubi.pt/pag/sousa-jorge-pedro-uma-historia-breve-do-jornalismo-no-ocidente.pdf>. Acesso em: 20 jul. 2013.

SMIT, J. W. A representação da imagem. Informare, Rio de Janeiro, v. 2, n. 2, p. 28-36, jul./dez. 1996.

TORREGROSA CARMONA, J. F. Modelos para el análisis documental de la fotografia. Documentación de las Ciencias de la Información, vol. 33, p. 329-342, 2010. Disponíve em: <http://revistas.ucm.es/index.php/DCIN/article/view/DCIN1010110329A>. Acesso em: 06 dez. 2014.

VASQUEZ. P. A. Fotografia escrita: nove ensaios sobre a produção fotográfica no Brasil. Rio de Janeiro, Senac, 2012. 


\section{Dados das autoras}

Raquel Juliana Prado Leite de Sousa

Mestre em Ciência, Tecnologia e Sociedade pela UFSCar, possui graduação em Biblioteconomia e Ciência da Informação pela UFSCar, em Comunicação Social - Jornalismo pela UNESP e licenciatura plena em Língua Portuguesa pelas FIMI. Tem experiência nas áreas de Biblioteconomia e Ciência da Informação, Jornalismo e Educação. Atualmente trabalha como Analista Sociocultural na Diretoria de Ensino - Região São João da Boa Vista. quel.leite@gmail.com

\section{Gabriela Aparecida da Cunha}

Graduanda em Biblioteconomia e Ciência da Informação pela Universidade Federal de São Carlos (UFSCar). Tem experiência na área de digitalização de acervo, base de dados referencial, construção de linguagens de representação do conhecimento, processamento técnico de documentos, organização e catalogação de periódicos científicos em Biblioteca Universitária, administração de Biblioteca Especializada no setor de Materiais Cerâmicos e gestão de projetos de agências de fomento.

gabrielacunha91@gmail.com

Recibido - Received: 2013-08-11

Aceptado - Accepted: 2013-12-30

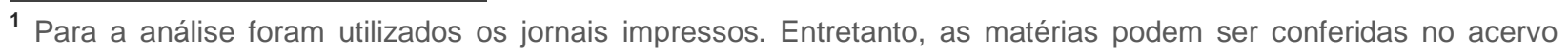
digital dos jornais:

O Estado de São Paulo - http://acervo.estadao.com.br/pagina/\#!/20130219-43589-nac-1-pri-a1-not

Folha de São Paulo - http://acervo.folha.com.br/fsp/2013/02/20/670

\section{$(c)$ EY}

This work is licensed under a Creative Commons Attribution 4.0

United States License.

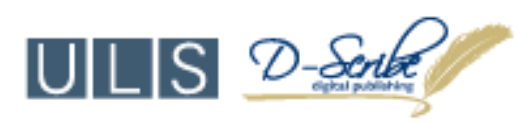

This journal is published by the University Library System of the University of Pittsburgh as part of its D-Scribe Digital Publishing Program and is cosponsored by the University of Pittsburgh Press. 